\title{
402 階層型領域分割法による大規模並列熱伝導解析
}

\author{
正 塩谷 隆二 (九州大), 正 金山 寛 (九州大)，○学石川 格 (九州大)
}

\section{Parallel Computing of Large Scale Heat Conductive Problems by Hierarchical Domain Decomposition Method}

\author{
Ryuji SHIOYA, Hiroshi KANAYAMA and Itaru ISHIKAWA \\ Kyushu University, Hakozaki 6-10-1, Higashi-ku Fukuoka
}

Key Words: Iterative Domain Decomposition, Parallel Computing, Finite Element Method, Heat Conductive Problem

\section{1. 概 要}

今日, 計算機による解析は高精度の解析結果に対する要求な どから,より大規模なモデルに対する解析が求められるように なってきている。しかし, 単一プロセッサでの処理は限界に近づ きつつあり，今後これ以上の計算速度を達成するためには,多重 プロセッサによる並列処理が必要不可欠である [1].

大規模問題を並列計算により効率良く解析するための数值解 析手法としては領域分割法が良く知られており，特に超大規模 の構造解析などに対して共役勾配法に基づく反復型領域分割法 の有効性が示されている，そこで著者らは100万自由度規模の 問題の解析を目標に, 定常熱伝導問題に対し反復型領域分割法 に基づく並列解析手法を導入した。

\section{2. 熱伝導問題の定式化}

ここでは,簡単のため境界条件として熱伝達境界条件や熱放 射境界条件は考慮せず,温度境界条件と熱流束境界条件のみが 与えられている問題を考える.Fig.1 に示すように多面体領域 $\Omega$ を考え, その境界を $\partial \Omega$, 境界上の外向き単位法線を $\nu$ とす る。この際, 領域 $\Omega$ 内には単位体積当たり $\bar{f}$ の内部発熱が存在 し，境界 $\Gamma_{u}$ 上に温度境界条件 $\bar{u}$ が，境界 $\Gamma_{Q}$ 上に熱流束境界条 件 $\bar{Q}$ が与えられているものとする. 全境界 $\partial \Omega$ は次式で与えら れる。

$$
\partial \Omega=\Gamma_{u}+\Gamma_{Q}
$$

温度を $u$, 熱流束ベクトルを $q$ とおくと, 全体領域 $\Omega$ において考
慮す心゙き系の方程式は, 以下のようになる $[2]$.

$$
\begin{array}{ll}
q_{i}=\lambda_{i j} u_{, j} & \text { in } \Omega \\
q_{i, i}+\bar{f}=0 & \text { in } \Omega \\
q_{i} \nu_{i}-\bar{Q}=0 & \text { on } \Gamma_{Q} \\
u=\bar{u} & \text { on } \Gamma_{u}
\end{array}
$$

ここで $\lambda_{i j}$ は熱伝導率を表し, 添字 ${ }_{j}$ は $j$ 方向に関する微分を 示すものとする.

\section{3. 反復型領域分割法}

Fig.2のように解析对象を 2 領域に分割した場合を考える. 上付き添宇 ${ }^{(k)}$ はその值が部分領域 $\Omega_{k}$ で定義されているこ とを示し，添字 ${ }^{(l)}$ はその值が部分領域 $\Omega_{k}$ に隣接する $\Omega_{l}$ で定 義されていることを示すものとする.部分領域 $\Omega_{k}, \Omega_{l}$ 間に新た に定義された境界を $\gamma_{k l}$ とおくと，問題 $(2) \sim(5)$ の解は以下の 式を満たす。

$$
\begin{array}{ll}
q_{i}^{(k)}=\lambda_{i j}^{(k)} u_{, j}^{(k)} & \text { in } \Omega^{(k)} \\
q_{i, i}^{(k)}+\bar{f}^{(k)}=0 & \text { in } \Omega^{(k)} \\
q_{i}^{(k)} \nu_{i}^{(k)}-\bar{Q}^{(k)}=0 & \text { on } \Gamma_{Q}^{(k)} \\
u^{(k)}=\bar{u}^{(k)} & \text { on } \Gamma_{u}^{(k)} \\
q_{i}^{(k)} \nu_{i}^{(k)}+q_{i}^{(l)} \nu_{i}^{(l)}=0 & \text { on } \gamma_{k l} \\
u^{(k)}=u^{(l)} & \text { on } \gamma_{k l}
\end{array}
$$

ここで, 境界条件の取り扱いを容易にするため，新しい変数 $\mu$ を 導入し, 式 (11) を以下のように変形する。

$$
u^{(k)}=u^{(l)} \equiv \mu \quad \text { on } \gamma_{k l}
$$

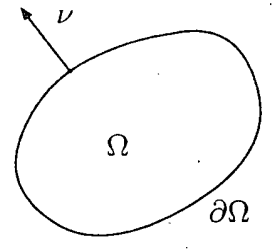

Fig. 1. Domain $\Omega$

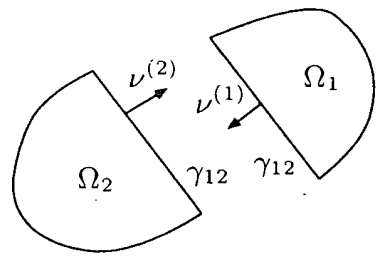

Fig. 2 Partition $\Omega$ into 2 subdomains 
Table. 1 Number of nodes, elements, and Interface DOF

\begin{tabular}{r|r|r|r|r}
\hline case & nodes & elements & domains & interface DOF \\
\hline I & 4,913 & 3,072 & 100 & 2,605 \\
II & 29,791 & 20,250 & 100 & 9,649 \\
III & 30,0763 & 215,622 & 600 & 94,908 \\
\hline
\end{tabular}

Table. 2 Itarations and CPU Time

\begin{tabular}{|r|r|r|}
\hline case & iterations & CPU time[sec] \\
\hline I & 124 & 532 \\
II & 168 & 4,230 \\
III & 326 & 107,872 \\
\hline
\end{tabular}

式 (10),(12) が部分領域間の境界で満たさ机るべき境界条件で あり，それぞれ熱流束および温度の連続性を示している.式 (12) を厳密に満足させ,式 (10) を積分形を用いて平均的な意味で満 足させることを考える。

まず,次のような対称・正定值である関数 $A$ を定義する.

$$
A(\mu)=-\left.\left(q_{i}^{(1)} \nu_{i}^{(1)}+q_{i}^{(2)} \nu_{i}^{(2)}\right)\right|_{\gamma_{12}}
$$

部分領域間境界における問題 $A(\mu)=0$ に対して,以下の共役勾 配法に基づくアルゴリズムを導入し，境界 $\gamma_{k l}$ 上の温度 $\mu$ を解 として求める

$$
\begin{aligned}
& \text { Chose } \mu^{0} ; \\
& g^{0}:=A\left(\mu^{0}\right) \\
& w^{0}:=g^{0} ; \\
& \text { for } n=0,1, \ldots ; \\
& \rho_{n}:=\frac{\left(g^{n}, g^{n}\right)}{\left(w^{n}, A\left(w^{n}\right)\right)} \\
& \mu^{n+1}:=\mu^{n}-\rho_{n} w^{n} ; \\
& g^{n+1}:=g^{n}-\rho_{n} A\left(w^{n}\right) ; \\
& \gamma_{n}:=\frac{\left\|g^{n+1}\right\|^{2}}{\left\|g^{n}\right\|^{2}} \\
& w^{n+1}:=g^{n+1}+\gamma_{n} w^{n} ; \\
& \text { If } \frac{\max _{i}\left|g^{n}\right|}{\max _{i}\left|g^{0}\right|}<\epsilon \text { break; } \\
& \text { end; }
\end{aligned}
$$

$$
\text { ここで } g^{0} \text { は }
$$

$$
\begin{array}{ll}
q_{i, i}^{(k)}+\bar{f}^{(k)}=0 & \text { in } \Omega^{(k)} \\
q_{i}^{(k)} \nu_{i}^{(k)}-\bar{Q}^{(k)}=0 & \text { on } \Gamma_{Q}^{(k)} \\
u^{(k)}=\bar{u}^{(k)} & \text { on } \Gamma_{u}^{(k)} \\
u^{(k)}=\mu^{0} & \text { on } \gamma_{12}
\end{array}
$$

を解いて得られる $q_{i, i}^{(1)}, q_{i, i}^{(2)}$ を用いて次式より求める.

$$
g^{0}=A\left(\mu^{0}\right)=-\left.\left(q_{i}^{(1)} \nu_{i}^{(1)}+q_{i}^{(2)} \nu_{i}^{(2)}\right)\right|_{\gamma_{12}}
$$

また, $A\left(w^{n}\right)$ は，

$$
\begin{array}{ll}
q_{i, i}^{(k)}=0 & \text { in } \Omega^{(k)} \\
q_{i}^{(k)} \nu_{i}^{(k)}=0 & \text { on } \Gamma_{Q}^{(k)} \\
u^{(k)}=0 & \text { on } \Gamma_{u}^{(k)} \\
u^{(k)}=w^{n} & \text { on } \gamma_{12}
\end{array}
$$

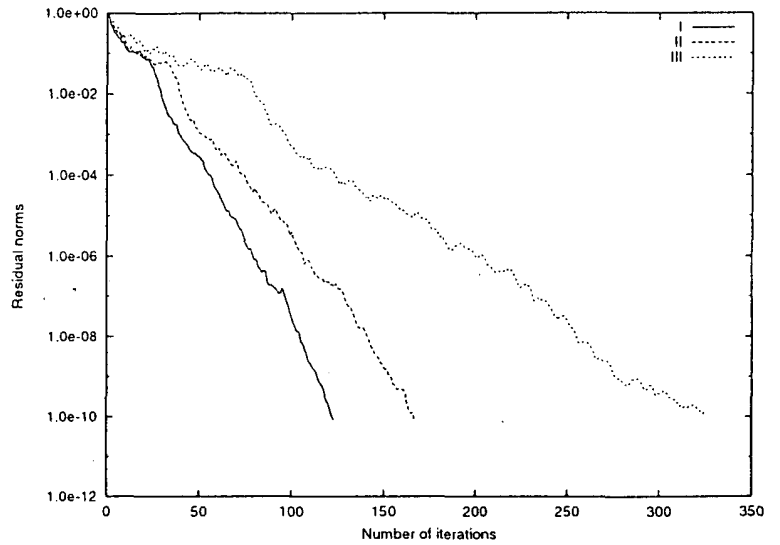

Fig. 3 Profile of residual norms

$$
\begin{aligned}
& \text { を解いて得られる } q_{i, i}^{(1)}, q_{i, i}^{(2)} \text { を用いて } \\
& \qquad A\left(w^{n}\right)=-\left.\left(q_{i}^{(1)} \nu_{i}^{(1)}+q_{i}^{(2)} \nu_{i}^{(2)}\right)\right|_{\gamma_{12}}
\end{aligned}
$$

\section{と計算できる。}

収束解として部分領域間の温度境界条件 $\mu$ が得ら机机ば，こ の $\mu$ を用いて式 (6) （9) および式 (12) をもう一度解くことに より, 全領域での解を得ることができる。

\section{4. 計 算 結 果}

上記のアルゴリズムに対して簡易モデルをもちいてテスト計 算を行った。簡易モデルとして正 6 面体を Table.1 に示すよう

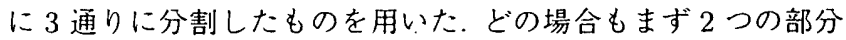
に部分分割し，そ机ぞれの部分をさらに領域に分割するという段 階的な領域分割を行い，階層型領域分割法 [1]による解析を行っ た．境界条件として上面および下面の温度を規定し，側面は全 て断熱とした。等方性を仮定し，熱伝導率の温度依存性はないも のとした．各場合の計算とも Sun Enterprise $(450 \mathrm{MHz})$ と Sun Ultra Sparc $(200 \mathrm{MHz})$ の 2 台を用いて並列計算を行った。 反復の収束の判定は

$$
\frac{\max _{i}\left|g^{(i)^{\prime \prime}}\right|}{\max _{i}\left|g^{(i)^{0}}\right|}<10^{-10}
$$

で行った

Fig.3 は反復回数に対する残差 $\max _{i}\left|g^{(i)^{\prime \prime}}\right| / \max _{i}\left|g^{(i)}\right|$ の 履歴である.いずれの場合も数百回程度の反復で収束解が得ら れた。

いずれの場合も解析結果は理論值と一致した。

Table.2 に収束までの反復回数および計算時間を示す.

\section{5. 結 論}

境界条件として温度境界条件と熱流束境界条件を考慮した定 常熱伝導問題に対し反復型領域分割法を導入し,30 万自由度規 模の問題に適用できることを示した。今後はより大規模な熱伝 導問題に対する並列計算および熱伝達境界を含む問題, 非定常 問題への本手法の適用を予定している。

\section{参考文献}

[1] 矢川元基, 塩谷隆二: 超並列有限要素解析, 朝倉書店, (1998)

[2] 下関正義, 藤沼平一: $P C-9801$ 有限要素法プログラミング の実際 [I], 日刊工業新聞社, (1989) 